Revista Brasil. Bot., V.32, n.1, p.143-153, jan.-mar. 2009

\title{
Variação ao longo do dia da atividade de enzimas do catabolismo de sacarose em plântulas de Hymenaea courbaril L. durante a mobilização do xiloglucano de reserva ${ }^{1}$
}

\author{
FÁBIO REIS DALLE MOLLE³, ALINE DIAS BRANDÃO² e MARCO AURÉLIO SILVA TINÉ3,4
}

(recebido: 02 de outubro de 2007; aceito: 18 de dezembro de 2008)

\begin{abstract}
Diurnal variation in the activity of enzymes of sucrose catabolism in Hymenaea courbaril L. plantlets during storage xyloglucan mobilization). Seeds of Hymenaea courbaril L. have a storage polysaccharide that is mobilized after germination, when the first leaf is already photosynthetic. During reserve mobilization, the seedling has to coordinate two carbohydrate sources: photosynthesis and storage mobilisation. Both use sucrose to export carbon. To understand the allocation of carbon resources in the seedling, therefore, it is essential to study the catabolism of sucrose in the organs. In the present work, the low molecular weight carbohydrates were analyzed, as well as the activity of sucrose synthase and of the three isoforms of invertase in organs of Hymenaea courbaril L. seedlings along a day. The analysis was made each 6 hours, with an extra analysis at $2 \mathrm{am}$. Each enzyme had a characteristic variation pattern along the day, suggesting distinct and independent functions for each organ. The carbohydrate analysis showed higher concentration of sucrose in the sink-organs, while the cotyledons had high concentration of free monosaccharides. The existence of isoforms with distinct properties and cellular distribution varying in independent ways along the day suggests that these isoforms may have distinct physiological functions in the plant.
\end{abstract}

Key words - cotyledons, germination, invertase, sucrose synthase, seed

RESUMO - (Variação ao longo do dia da atividade de enzimas do catabolismo de sacarose em plântulas de Hymenaea courbaril L. durante a mobilização do xiloglucano de reserva). Sementes de Hymenaea courbaril L. possuem um polissacarídeo de reserva que é mobilizado após a germinação, quando a primeira folha da planta já é fotossinteticamente ativa. No momento da mobilização das reservas, a plântula precisa coordenar duas fontes de carboidratos: a fotossíntese e a mobilização das reservas. Ambos geram sacarose como forma de exportação de carbono. Para entender a alocação de recursos na plântula, portanto, é necessário avaliar o catabolismo de sacarose nos órgãos. Neste trabalho foram analisados os carboidratos de baixo peso, quantificada a atividade da sacarose sintase e das três isoformas de invertase nos diferentes órgãos de plântulas de H. courbaril ao longo de um dia. As dosagens foram feitas no período de mobilização do xiloglucano, sendo as plântulas coletadas em intervalos de 6 horas, com uma coleta extra às 2 horas da manhã. Cada uma das enzimas apresentou um padrão característico de variação ao longo do dia, sugerindo funções distintas e independentes em cada órgão. A análise dos carboidratos mostrou altas concentrações de sacarose nos órgãos-dreno, enquanto os cotilédones apresentaram altas concentrações de monossacarídeos livres. A existência de isoformas com propriedades e distribuição celular distintas variando de forma independente ao longo do dia sugere que as isoformas podem ter funções fisiológicas distintas dentro da planta.

Palavras-chave - cotilédones, germinação, invertase, sacarose sintase, semente

\section{Introdução}

O gênero Hymenaea surgiu na África há cerca de 65 milhões de anos, espalhou-se e adaptou-se muito bem nas regiões neotropicais gerando muitas espécies (Lee \& Langenheim 1975). Hymenaea courbaril L. é

1. Parte da dissertação de mestrado do primeiro autor, Programa de Pós-graduação do Instituto de Botânica da Secretaria de Estado do Meio Ambiente, São Paulo, SP, Brasil.

2. Universidade Estadual de Campinas, Instituto de Biologia Programa de Pós-Graduação em Biologia Celular e Estrutural, 13042-013 Campinas, SP, Brasil.

3. Instituto de Botânica, Seção de Fisiologia e Bioquímica de Plantas, Caixa Postal 3005, 01061-960 São Paulo, SP, Brasil.

4. Autor para correspondência: marco.tine@gmail.com considerada uma das mais bem-sucedidas espécies deste gênero, com 17 variedades diferentes distribuídas desde florestas tropicais do México até os países tropicais da América do Sul. Esta espécie é típica de floresta madura, sendo considerada espécie secundária tardia (ou clímax) na sucessão florestal (Lee \& Langenheim 1975), possui sementes grandes com cotilédones globóides nãofotossintetizantes ricos em reservas (Buckeridge \& Dietrich 1990), as quais são importantes na estratégia da espécie para o estabelecimento das plântulas.

O estabelecimento das plântulas durante o crescimento heterotrófico envolve o uso metabolicamente controlado das reservas (mobilização e partição dos produtos) até que as plantas sejam capazes de extrair do ambiente os recursos necessários ao seu crescimento. Esta transição 
do estado heterotrófico para a autotrofia é considerada como uma etapa crítica no ciclo de vida das plântulas, com conseqüências para o crescimento inicial e sobrevivência (Santos \& Buckeridge 2004). Portanto, a compreensão do controle do metabolismo das reservas é essencial para entender a estratégia de uso dos recursos disponíveis para as plântulas.

A espécie $H$. courbaril é conhecida por acumular na parede celular do tecido cotiledonar um polissacarídeo de reserva denominado xiloglucano, que corresponde a $40 \%$ da massa seca dos cotilédones. Este polissacarídeo é mobilizado após a germinação durante o desenvolvimento da plântula (Tiné et al. 2000). A mobilização do xiloglucano é máxima durante a expansão dos metáfilos (folhas compostas) (Santos \& Buckeridge 2004), período no qual os eófilos já são fotossinteticamente ativos (Barriga 2003). Neste período a planta possui, portanto, duas fontes de carboidratos: a fotossíntese dos eófilos e a reserva cotiledonar. Trabalho anterior com $H$. courbaril (Amaral 2005) mostrou variação das atividades das enzimas do metabolismo do xiloglucano ao longo do dia, com maior atividade de degradação do xiloglucano ocorrendo à noite. $\mathrm{O}$ metabolismo das duas fontes de carbono da planta, portanto, parece estar sincronizado de modo que o eixo embrionário tenha um fornecimento de carbono ao longo de todo o dia.

Embora o mecanismo bioquímico da degradação do xiloglucano já tenha sido estudado, sabe-se pouco sobre o transporte de carbono entre as partes da planta. A ausência de outros oligossacarídeos, além da sacarose, nos cotilédones de $H$. courbaril durante a mobilização do xiloglucano, sugere que este dissacarídeo seja a forma de transporte de carbono predominante entre o órgão fonte (cotilédone à noite ou eófilo durante o dia) e os drenos (raiz, caule, folhas em expansão) (Farrar et al. 2000). A própria disponibilidade de sacarose nos tecidos poderia funcionar como um sinalizador no processo, uma vez que além de fonte de energia, a própria sacarose pode atuar como um regulador direto ou indireto da expressão gênica (Winter \& Huber 2000). Estudar o metabolismo de sacarose neste período tão crítico do ciclo de vida da planta, portanto, é essencial para entender as relações fonte e dreno e a alocação de recursos e uso do carbono na planta.

As principais enzimas do metabolismo de sacarose são a sacarose fosfato sintase (SPS) (EC 2.4.1.14), a sacarose sintase (SuSy) (EC 2.4.1.13) e a invertase (EC 3.2.1.26). A síntese de sacarose é realizada principalmente pela SPS, uma enzima alostérica ativada pela glucose6-fosfato e inibida pelo ortofosfato (Taiz \& Zeiger 2003). A degradação da sacarose, e consequentemente, o estabelecimento do dreno, pode ser realizada tanto pela SuSy quanto pela invertase. Existem pelo menos duas isoformas de SuSy, sendo ambas citoplasmáticas solúveis, mas podem apresentar-se fortemente aderidas ao complexo de celulose sintase na membrana plasmática ou no citoesqueleto, dependendo do estado de fosforilação (Sturm \& Tang 1999). Existem pelo menos três isoformas de invertase nos tecidos, as quais diferem entre si pela localização celular e propriedades, de modo que é possível distinguir a atividade em cada um dos compartimentos celulares pela propriedade da enzima que se está dosando. Uma das isoformas está localizada no vacúolo, é solúvel e possui $\mathrm{pH}$ ótimo em torno de 4,6. Outra isoforma está presente na parede celular, é insolúvel e também possui $\mathrm{pH}$ ótimo em torno de 4,6. A terceira isoforma está localizada no citoplasma, é solúvel e possui pH ótimo em torno de 7,0. Aparentemente, as atividades dessas invertases são independentes e possuem funções distintas, sendo que cada célula pode apresentar as diferentes isoformas em diferentes proporções. Alterações das atividades das enzimas de degradação da sacarose por expressão antisense em cenoura (Sturm \& Tang 1999) mostraram efeitos distintos na formação do órgão de reserva como redução do acúmulo de carboidratos, redução do crescimento do órgão de reserva e alteração da razão raiz:parte aérea.

Como contribuição para o estudo do metabolismo de carboidratos em $H$. courbaril, o presente trabalho se propõe a mapear as atividades da sacarose sintase e de três isoformas de invertase, nos diferentes órgãos da plântula ao longo do dia, durante a mobilização do xiloglucano de reserva.

\section{Material e métodos}

Aproximadamente $1,0 \mathrm{~kg}$ de sementes de $H$. courbaril L. var. stilbocarpa (Hayne) Y. T. Lee \& Langenh. foram adquiridas no Instituto Florestal de São Paulo. As sementes foram escarificadas mecanicamente e embebidas em bandejas com papel de filtro em câmaras de crescimento a $30^{\circ} \mathrm{C} \mathrm{com}$ fotoperíodo de 12 horas. Após a germinação, por volta de 40 dias depois do início da embebição, as sementes foram colocadas em vasos com a mistura vermiculita-areia (1:2) e mantidas em casa de vegetação por cerca de 40 dias até a coleta, quando a mobilização do polissacarídeo de reserva atingiu sua taxa máxima, evidenciada pelo enrugamento dos cotilédones (Tiné et al. 2000).

Para o mapeamento das atividades das enzimas e dos teores de carboidratos solúveis foram utilizadas plântulas coletadas às $0 \mathrm{~h} 00,2 \mathrm{~h} 00,6 \mathrm{~h} 00,12 \mathrm{~h} 00$ e $18 \mathrm{~h} 00$. Três plântulas foram coletadas em cada horário, padronizando-se a amostragem pelo tamanho e estádio de desenvolvimento 
das plântulas, as quais foram imediatamente congeladas e mantidas a $-80{ }^{\circ} \mathrm{C}$ até a análise. A coleta no horário das $2 \mathrm{~h} 00$ foi feita com base nos dados de Amaral (2005) que indica este horário como sendo o de máxima atividade das enzimas de degradação do xiloglucano de reserva e, portanto, o provável horário de sua máxima mobilização. Os diferentes órgãos das plântulas (raiz, hipocótilo, cotilédones, eófilo, metáfilo e epicótilo) foram separados e processados de forma independente.

A extração da SuSy foi feita com homogeneização dos órgãos da plântula em banho de gelo com tampão Tris $\mathrm{HCl}$ $100 \mathrm{mM} \mathrm{pH}$ 7,5 com $50 \mathrm{mM} \mathrm{NaCl}, 0,2 \mathrm{mM}$ phenylmethylsulfonyl fluoride (PMSF), $5 \mathrm{mM}\left(\mathrm{NH}_{4}\right)_{2} \mathrm{C}_{2} \mathrm{O}_{4} \cdot \mathrm{H}_{2} \mathrm{O}, 10 \mathrm{mM} \mathrm{MgCl} 2$, na proporção de $5 \mathrm{~mL}$ de tampão por grama de matéria fresca da amostra. O extrato bruto foi centrifugado a $13.000 \mathrm{~g}$ por 10 minutos a $4{ }^{\circ} \mathrm{C}$. A fração solúvel foi dialisada contra tampão Tris $\mathrm{HCl} 25 \mathrm{mM}$ pH 7,5 com $50 \mathrm{mM} \mathrm{NaCl}, 2 \mathrm{mM} \mathrm{MgCl}_{2}$. A diálise teve duração de duas horas, com a troca da solução tampão de 30 em 30 minutos, sendo realizada a $4{ }^{\circ} \mathrm{C}$. No final da diálise foram medidos os volumes dos extratos enzimáticos dos diferentes órgãos da plântula.

$\mathrm{O}$ ensaio para a quantificação da atividade da SuSy foi feito no sentido de síntese de sacarose e foi constituído de três etapas, descritas a seguir:

I - Ensaio da SuSy: $300 \mu \mathrm{L}$ de extrato enzimático, 300 $\mu \mathrm{L}$ de tampão de ensaio contendo tampão Tris- $\mathrm{HCl} 25 \mathrm{mM}$ $\mathrm{pH}$ 7,5, $40 \mathrm{mM} \mathrm{MgCl}_{2}, 30 \mathrm{mM}$ frutose e $20 \mathrm{mM}$ UDPglucose. Este sistema foi incubado por 20 minutos a $30^{\circ} \mathrm{C}$.

II - Hidrólise da sacarose formada: foram adicionados ao sistema de ensaio resultante da etapa anterior $50 \mu \mathrm{L}$ de ácido acético $500 \mathrm{mM}$, levando a concentração final de ácido acético a 31,25 mM, e $150 \mu \mathrm{L}$ de invertase (Sigma 852 unidades $\mathrm{mL}^{-1}$ ), o que leva a uma atividade total de 127,8 unidades $\mathrm{mL}^{-1}$. O sistema foi incubado por 10 minutos a $30{ }^{\circ} \mathrm{C}$.

III - Dosagem de glucose livre: após a incubação com invertase, a glucose livre produzida pela ação da invertase foi quantificada pela adição de $100 \mu \mathrm{L}$ de tampão Tris $\mathrm{HCl}$ $1,0 \mathrm{M} \mathrm{pH} \mathrm{8,0} \mathrm{(levando} \mathrm{a} \mathrm{concentração} \mathrm{final} \mathrm{a} 111 \mathrm{mM}$ ) e $600 \mu \mathrm{L}$ de solução de dosagem de glicose (LabTest). Nesta etapa, o sistema foi incubado por mais 10 minutos a $30^{\circ} \mathrm{C}$. A absorbância foi determinada a $505 \mathrm{~nm}$.

Para determinação da atividade de invertase, foi produzido um extrato enzimático dos diferentes órgãos da planta por homogeneização dos tecidos em banho de gelo com tampão Tris $\mathrm{HCl} 10 \mathrm{mM}$ pH 6,5 na proporção de $5 \mathrm{~mL}$ de tampão por grama de matéria fresca da amostra. Após a homogeneização, o extrato bruto foi centrifugado por 10 minutos a $13.000 \mathrm{~g}$. O extrato bruto solúvel foi dialisado a $4{ }^{\circ} \mathrm{C}$ contra tampão Tris $10 \mathrm{mM} \mathrm{pH} \mathrm{6,5} \mathrm{durante} \mathrm{quatro} \mathrm{horas,}$ com troca de tampão de hora em hora. Ao final da diálise o volume dos extratos enzimáticos dos diferentes órgãos da plântula foi medido. O sedimento insolúvel foi lavado 3 vezes com $500 \mu \mathrm{L}$ de tampão acetato de sódio 50 mM pH 4,6, sendo usado para a determinação da atividade de invertase insolúvel.

As condições de ensaio da invertase insolúvel foram as seguintes: $75 \mathrm{mg}$ de sedimento insolúvel, $250 \mu \mathrm{L}$ de tampão

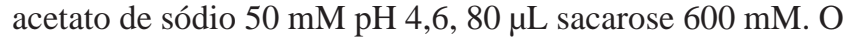
sistema após agitado foi incubado por 20 minutos a $30{ }^{\circ} \mathrm{C}$. Após fervura por dois minutos e um pulso de centrifugação de $13.000 \mathrm{~g}, 250 \mu \mathrm{L}$ do sistema foram transferidos para um tubo contendo $625 \mu \mathrm{L}$ de tampão Tris $100 \mathrm{mM} \mathrm{pH} \mathrm{8,0} \mathrm{e} 500 \mu \mathrm{L}$ de solução de dosagem de glucose (LabTest). O sistema foi incubado por 10 minutos a $30{ }^{\circ} \mathrm{C}$. Deste extrato foi lida a absorbância a $505 \mathrm{~nm}$ e a quantidade de glucose liberada quantificada por comparação com curva padrão de glucose.

As condições de ensaio da invertase solúvel ácida foram as seguintes: $200 \mu \mathrm{L}$ de extrato enzimático, $10 \mu \mathrm{L}$ ácido acético $50 \mathrm{mM}, 80 \mu \mathrm{L}$ sacarose $600 \mathrm{mM}$. Este sistema foi incubado a $30{ }^{\circ} \mathrm{C}$ por 20 minutos e fervido por dois minutos. Foram adicionados $40 \mu \mathrm{L}$ de tampão Tris $100 \mathrm{mM}$ pH 8,0 e $500 \mu \mathrm{L}$ de solução de dosagem de glucose (LabTest). O sistema foi incubado por 10 minutos a $30^{\circ} \mathrm{C}$. O procedimento de dosagem de glucose foi o mesmo descrito acima.

As condições de ensaio da invertase solúvel neutra foram: $200 \mu \mathrm{L}$ de extrato enzimático, $80 \mu \mathrm{L}$ sacarose $600 \mathrm{mM}$. Este sistema foi incubado por 10 minutos a $30^{\circ} \mathrm{C}$ e logo após foi fervido por dois minutos. Foram adicionados $500 \mu \mathrm{L}$ de solução de dosagem de glucose (LabTest) e o sistema foi incubado por mais 10 minutos a $30^{\circ} \mathrm{C}$. A dosagem de glucose foi a mesma descrita acima.

Os teores de proteína dos extratos de SuSy e invertase foram determinados usando $50 \mu \mathrm{L}$ de extrato enzimático, $750 \mu \mathrm{L}$ de água e $200 \mu \mathrm{L}$ de solução de Bradford (BioRad) de acordo com as instruções do fabricante. A absorbância foi determinada a $595 \mathrm{~nm}$. A quantidade de proteína foi determinada por comparação com uma curva padrão de albumina bovina sérica.

Para a análise de carboidratos, amostras dos tecidos congelados das plântulas foram liofilizadas, maceradas, colocadas em tubos Eppendorf de 2,0 mL e pesadas. A extração dos açúcares foi feita com $400 \mu \mathrm{L}$ de etanol $80 \%$, em banho por 10 minutos a $80^{\circ} \mathrm{C}$, seguida por centrifugação e retirada do sobrenadante. Este procedimento foi repetido 5 vezes, perfazendo 2,0 $\mathrm{mL}$ de sobrenadante submetido a posterior secagem em baixa pressão com centrifugação (Hetovac). O material seco foi retomado em 1,0 mL de água e o teor de açúcares foi determinado pelo método fenolsulfúrico (Dubois et al. 1956). Em um tubo de vidro, foram acrescentadas uma alíquota da amostra a ser dosada juntamente com água para o volume final de $0,5 \mathrm{~mL}, 0,5 \mathrm{~mL}$ de fenol e 2,5 mL de ácido sulfúrico com homogeneização vigorosa, para posterior leitura da absorbância a 490 nm. A quantificação de açúcar foi feita por comparação com curva padrão de glucose.

Os monossacarídeos e oligossacarídeos presentes nas frações de material solúvel em etanol foram analisados por cromatografia de troca aniônica de alta performance associada à detecção por pulso amperométrico (HPAECPAD) com coluna Carbo-Pac PA1 em eluição isocrática com $\mathrm{NaOH} 150 \mathrm{mM}$ por 20 minutos. Os carboidratos foram identificados e quantificados por comparação com os perfis de eluição de padrões comerciais. 
As análises estatísticas foram determinadas pela análise de variância (ANOVA) utilizando o Winstat para Excel. O teste de diferença entre as médias foi o "least significant diferences" (LSD) com nível de significância de $5 \%$.

\section{Resultados}

A atividade específica da SuSy mostrou variação em alguns órgãos da plântula, exceto epicótilo (figura $1 \mathrm{E})$, sendo que ao final do período luminoso foi constatada elevada atividade de SuSy na maioria dos
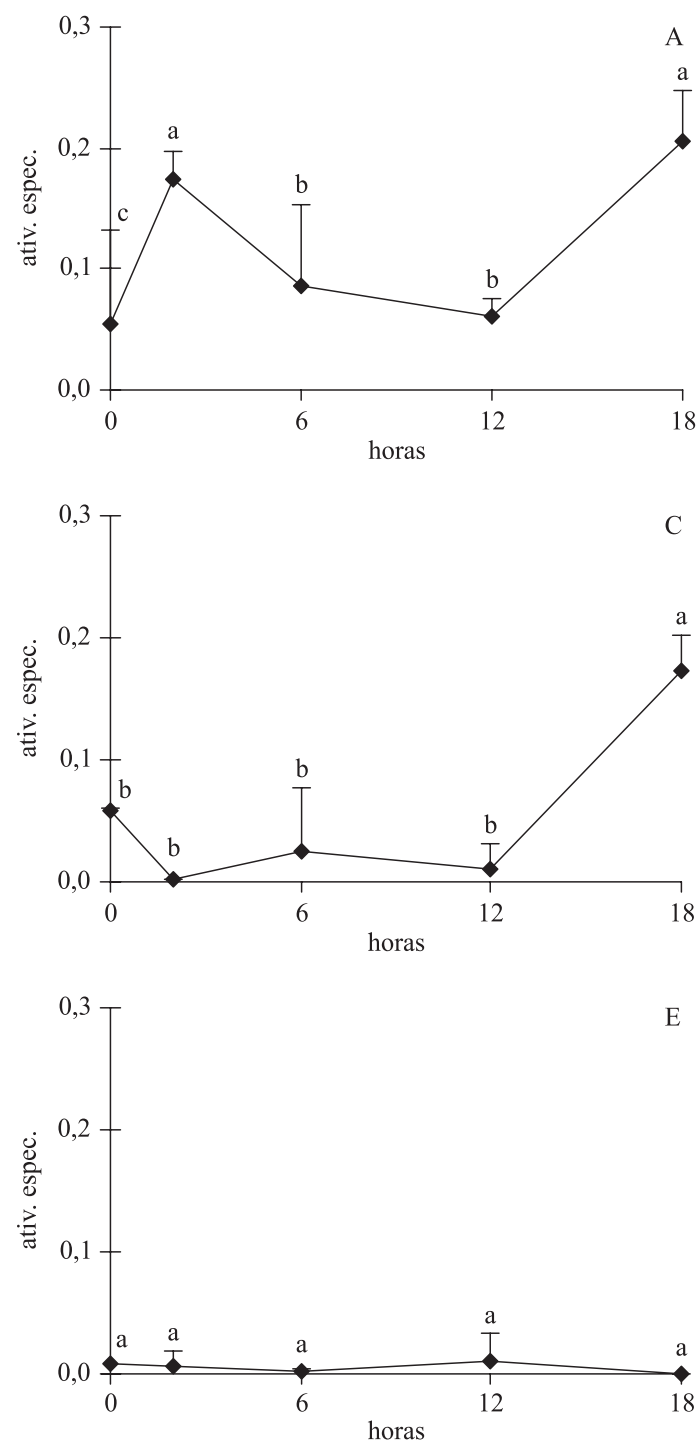

órgãos da plântula. Em hipocótilo e cotilédone houve um pico de atividade às 18 h00 (figura $1 \mathrm{~B}$ e C). Raiz e eófilo apresentaram um padrão bifásico de atividade com predominância de elevação de atividade às $18 \mathrm{~h} 00 \mathrm{e}$ diminuição aos menores valores de atividade específica por volta das 6 h00 (figura $1 \mathrm{~A}$ e D). O metáfilo também apresentou um padrão bifásico, com elevadas atividades de SuSy às $0 \mathrm{~h} 00$ e às $12 \mathrm{~h} 00$ (figura $1 \mathrm{~F}$ ).

Os resultados de atividade das 3 isoformas de invertase foram expressos por grama de matéria fresca, devido à impossibilidade de solubilização em tampão
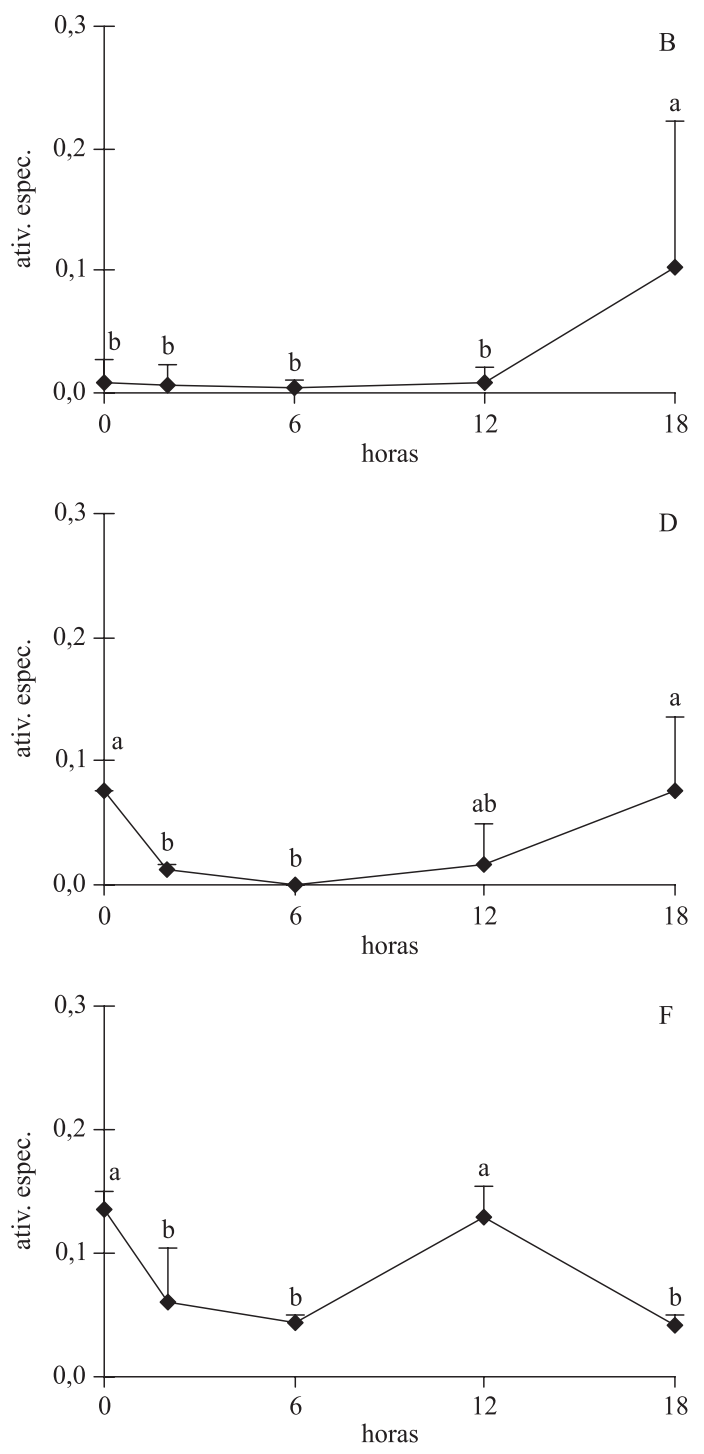

Figura 1. Atividade específica ( $\mu \mathrm{g}$ sacarose $\min ^{-1} \mu \mathrm{g}^{-1}$ proteína) de sacarose sintase nos órgãos de plântulas de H. courbaril ao longo do dia. $(\mathrm{A}=$ raiz; $\mathrm{B}=$ hipocótilo; $\mathrm{C}=$ cotilédone; $\mathrm{D}=$ eófilo; $\mathrm{E}=$ epicótilo e $\mathrm{F}=$ metáfilo. Barras verticais representam desvio padrão). Letras diferentes correspondem a diferenças significativas $(P=0,05) n=3$.

Figure 1. Specific activity ( $\mu \mathrm{g}$ sucrose $\min ^{-1} \mu \mathrm{g}^{-1}$ protein) of sucrose synthase in the organs of plantlets of $H$. courbaril along the day. $(\mathrm{A}=$ root; $\mathrm{B}=$ hypocotyl; $\mathrm{C}=$ cotyledon; $\mathrm{D}=$ eophyll; $\mathrm{E}=$ epicotyl and $\mathrm{F}=$ metaphyll). Vertical bars represent standard deviation. Different letters mean statistically significant differences $(P=0.05) n=3$. 
Tris da isoforma insolúvel, razão pela qual não é possível expressá-la como atividade específica. Desta forma, foi possível comparar as atividades das três isoformas. No geral, as maiores atividades foram encontradas na isoforma insolúvel da invertase (figura 2). Para esta invertase, as maiores atividades foram encontradas na raiz e no metáfilo (figura 2A e F), embora apenas no metáfilo a variação ao longo do dia tenha se mostrado significativa. Nestes órgãos a atividade permaneceu acima dos $10 \mu \mathrm{g}$ de glucose min $^{-1} \mathrm{~g}^{-1}$ de matéria fresca, chegando a $50 \mu \mathrm{g}$ de glucose $\min ^{-1} \mathrm{~g}^{-1}$
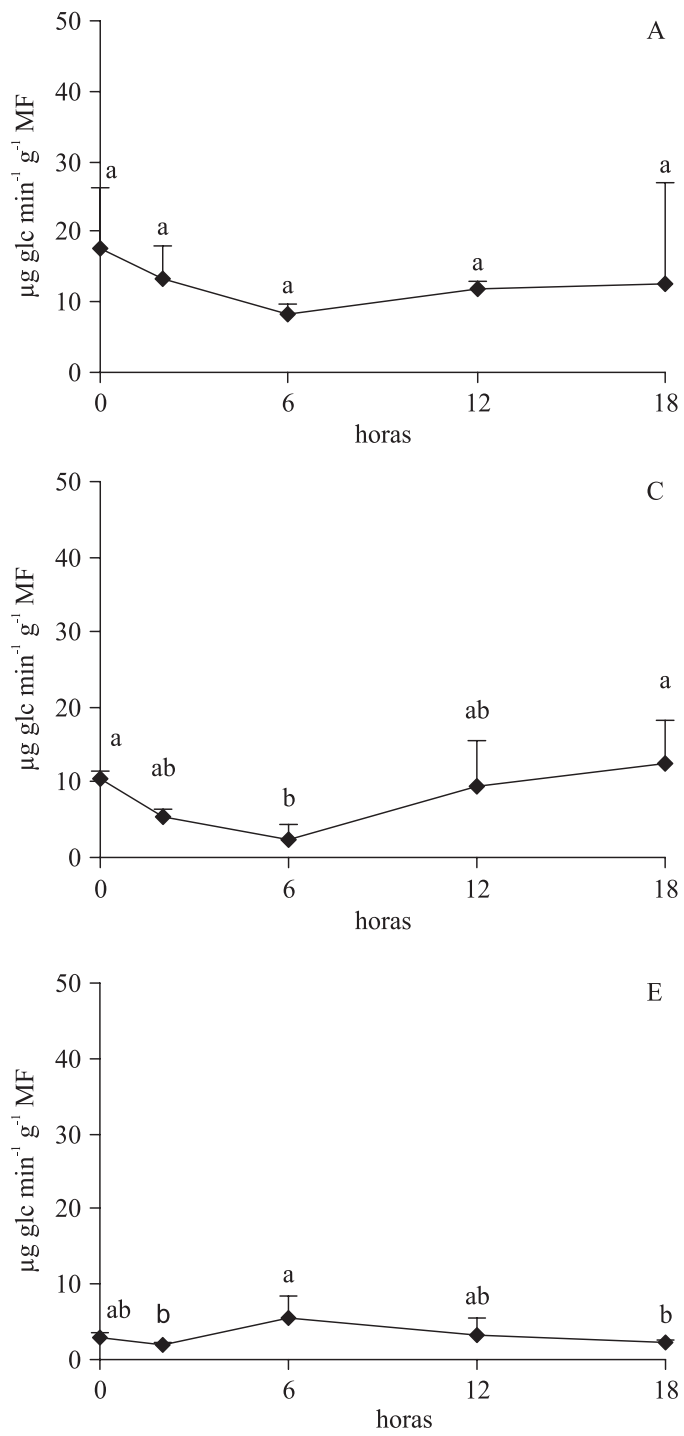

de matéria fresca no metáfilo. Embora a atividade tenha sido menor nos demais órgãos, em todos eles foram observadas variações estatisticamente significativas ao longo do dia. Em especial, logo ao amanhecer (6h00), foi observada a maior atividade de invertase no hipocótilo e no epicótilo, enquanto nos cotilédones e no eófilo neste mesmo horário foram observadas as menores atividades.

Em todos os órgãos foram observadas variações significativas de atividade de invertase solúvel ácida (figura 3). Em todos os órgãos, foi observado um
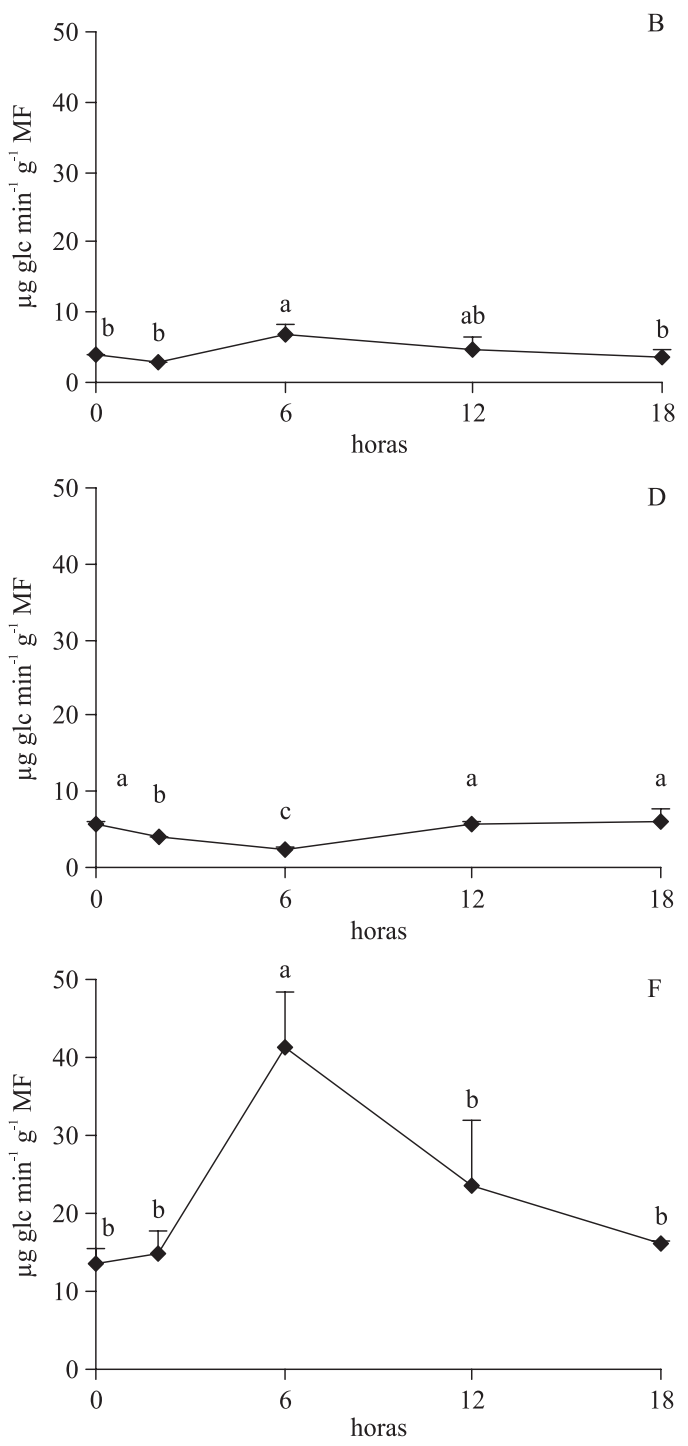

Figura 2. Atividade de invertase insolúvel ( $\mu$ g glucose $\min ^{-1} \mathrm{~g}^{-1}$ de massa fresca) nos órgãos de plântulas de $H$. courbaril ao longo do dia. ( $\mathrm{A}=$ raiz, $\mathrm{B}=$ hipocótilo, $\mathrm{C}=$ cotilédone, $\mathrm{D}=$ eófilo, $\mathrm{E}=$ epicótilo e $\mathrm{F}=$ metáfilo). Barras verticais representam desvio padrão. Letras diferentes correspondem a diferenças estatisticamente significativas $(P=0,05) n=3$.

Figure 2. Insoluble invertase activity ( $\mu$ g glucose $\min ^{-1} \mathrm{~g}^{-1}$ fresh weight) in the organs of plantlets of $H$. courbaril along the day. $(\mathrm{A}=$ root, $\mathrm{B}=$ hypocotyl, $\mathrm{C}=$ cotyledon, $\mathrm{D}=$ eophyll, $\mathrm{E}=$ epicotyl and $\mathrm{F}=$ metaphyll). Vertical bars represent standard deviation. Different letters mean statistically significant differences $(P=0.05) n=3$. 
aumento da atividade às $2 \mathrm{~h} 00 \mathrm{e}$, no caso do cotilédone, a atividade voltou a aumentar no início da noite. As maiores atividades foram obtidas no cotilédone às $18 \mathrm{~h} 00$ e no metáfilo às $2 \mathrm{~h} 00$ (figura $3 \mathrm{C} \mathrm{e} \mathrm{F}$ ), com o valor de $8,0 \mu \mathrm{g}$ de glucose $\min ^{-1} \mathrm{~g}^{-1}$ de matéria fresca. Nos outros órgãos a atividade oscilou entre 0 e 3,0 $\mu$ g de glucose $\min ^{-1} \mathrm{~g}^{-1}$ de matéria fresca ao longo do dia.

A invertase solúvel neutra apresentou as menores atividades dentre as isoformas, com valor máximo de 6,0 $\mu \mathrm{g}$ de glucose $\min ^{-1} \mathrm{~g}^{-1}$ de matéria fresca no hipocótilo
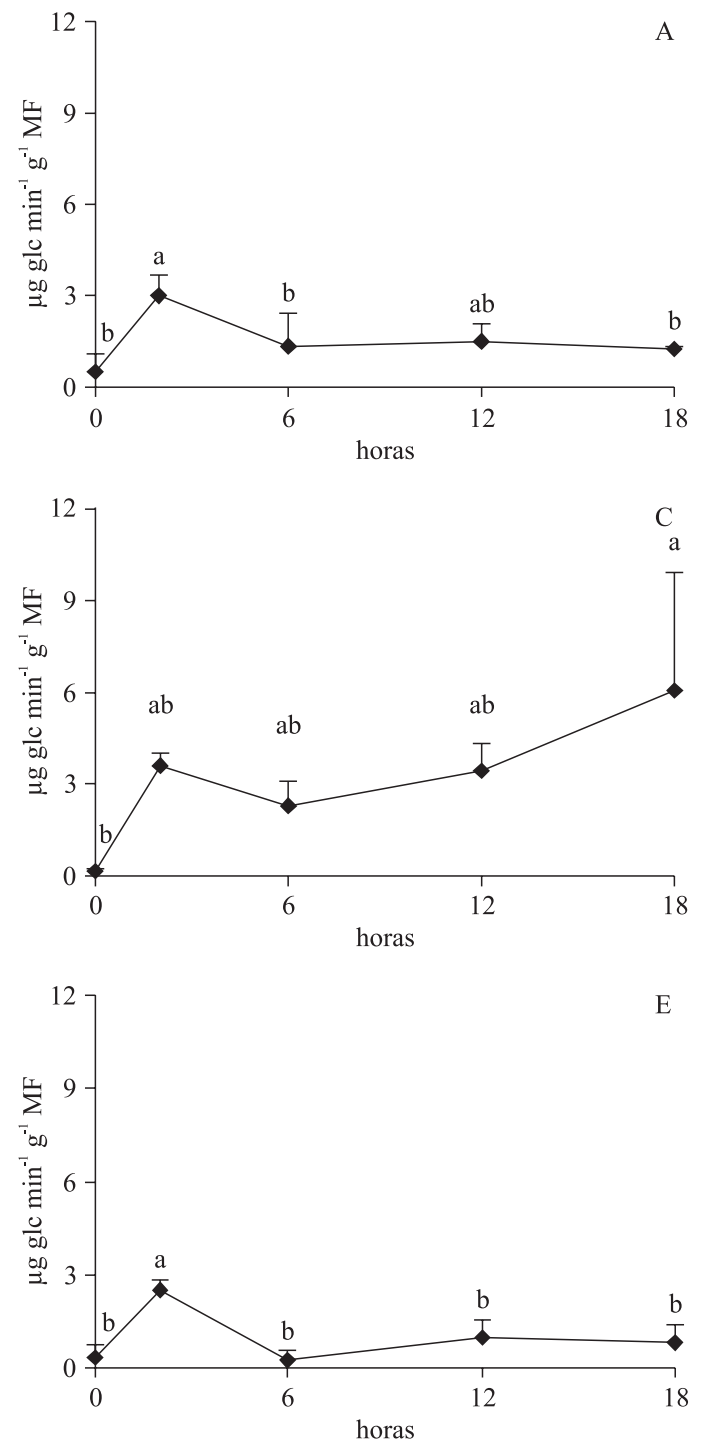

e no cotilédone às $18 \mathrm{~h} 00$ (figura 4B e C). A atividade desta isoforma ficou na raiz e no metáfilo entre 0 e 3,0 $\mu \mathrm{g}$ de glucose $\min ^{-1} \mathrm{~g}^{-1}$ de matéria fresca ao longo do dia (figura $4 \mathrm{~A}$ e F). No eófilo e no epicótilo (figura 4D e E) foram registradas as menores atividades dentre todas as isoformas, que permaneceram próximas de 0 durante todo dia, embora com variação significativa às $12 \mathrm{~h} 00$. Exceto pela raiz, foram observadas variações significativas da atividade em todos os órgãos. No cotilédone, a atividade aumentou gradualmente ao longo de todo o experimento,
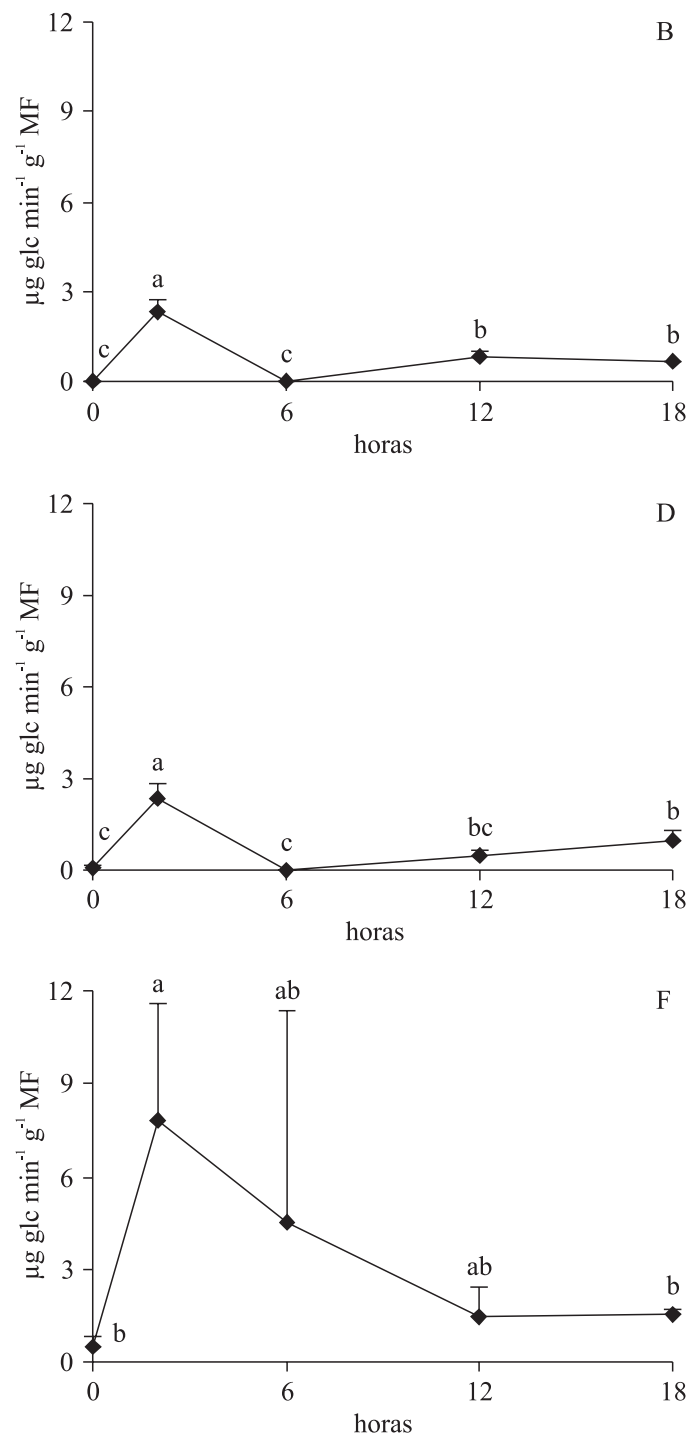

Figura 3. Atividade de invertase solúvel ácida ( $\mu \mathrm{g}$ glucose $\min ^{-1} \mathrm{~g}^{-1}$ de peso fresco) nos órgãos de plântulas de $H$. courbaril ao longo do dia. $(\mathrm{A}=$ raiz, $\mathrm{B}=$ hipocótilo, $\mathrm{C}=$ cotilédone, $\mathrm{D}=$ eófilo, $\mathrm{E}=$ epicótilo e $\mathrm{F}=$ metáfilo). Barras verticais representam desvio padrão. Letras diferentes correspondem a diferenças significativas $(P=0,05) n=3$.

Figure 3. Acid soluble invertase activity ( $\mu$ g glucose $\min ^{-1} \mathrm{~g}^{-1}$ fresh weight) in the organs of plantlets of $H$. courbaril along the day. $(\mathrm{A}=$ root, $\mathrm{B}=$ hypocotyl, $\mathrm{C}=$ cotyledon, $\mathrm{D}=$ eophyll, $\mathrm{E}=$ epicotyl and $\mathrm{F}=$ metaphyll). Vertical bars represent standard deviation. Different letters mean statistically significant differences $(P=0.05) n=3$. 

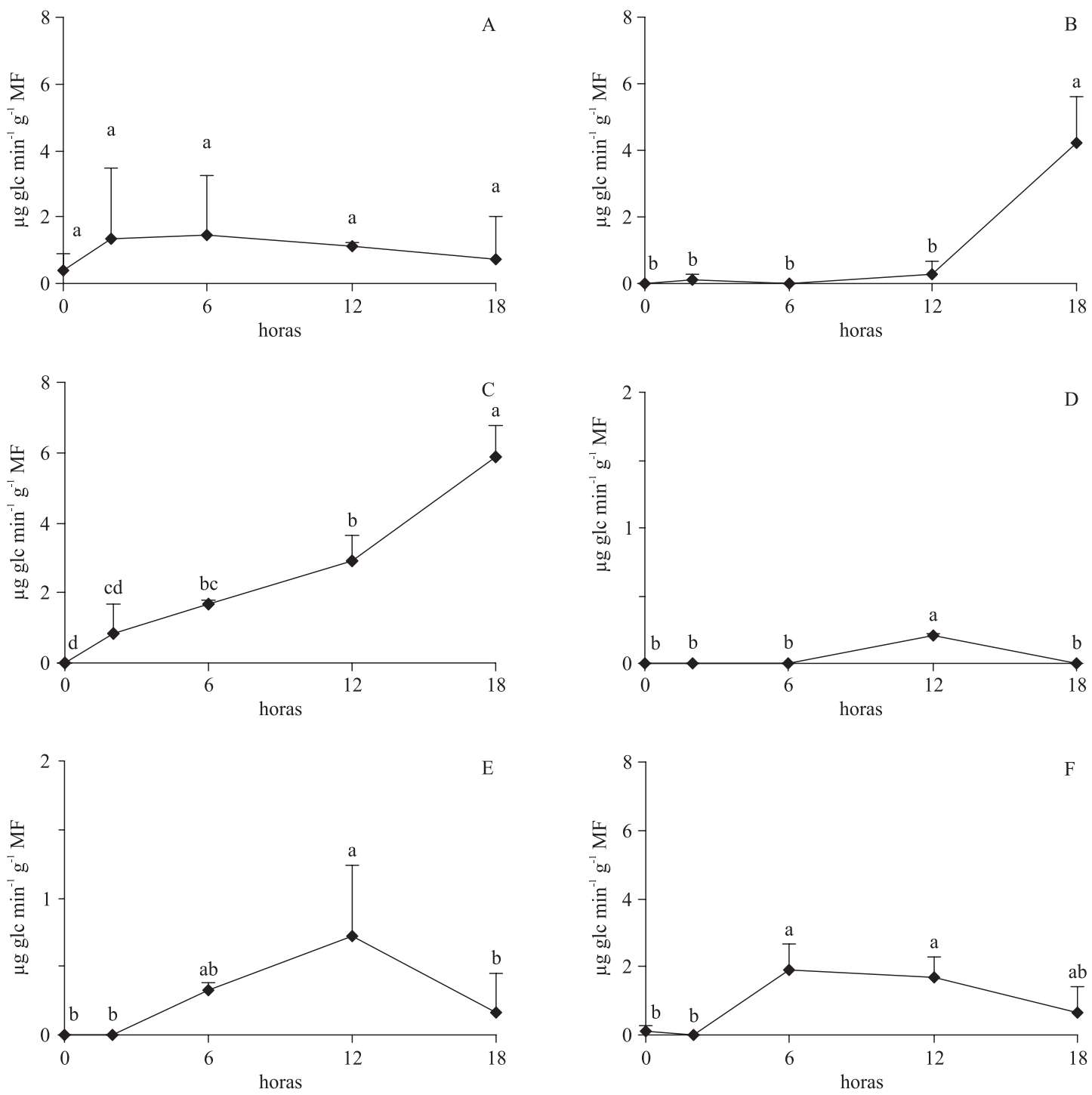

Figura 4. Atividade de invertase solúvel neutra ( $\mu$ g glucose $\min ^{-1} \mu \mathrm{g}^{-1}$ de peso fresco) nos órgãos de plântulas de $H$. courbaril ao longo do dia. ( $\mathrm{A}=$ raiz, $\mathrm{B}=$ hipocótilo, $\mathrm{C}=$ cotilédone, $\mathrm{D}=$ eófilo, $\mathrm{E}=$ epicótilo e $\mathrm{F}=$ metáfilo). Nas figuras $\mathrm{D}$ e $\mathrm{E}$ o eixo das abscissas está diferente dos demais para melhor visualização dos dados. Barras verticais representam desvio padrão. Letras diferentes correspondem a diferenças significativas $(P=0,05) n=3$.

Figure 4. Neutral soluble invertase activity ( $\mu$ g glucose $\min ^{-1} \mathrm{~g}^{-1}$ fresh weight) in the organs of plantlets of $H$. courbaril along the day. $(\mathrm{A}=$ root, $\mathrm{B}=$ hypocotyl, $\mathrm{C}=$ cotyledon, $\mathrm{D}=$ eophyll, $\mathrm{E}=$ epicotyl and $\mathrm{F}=$ metaphyll). In the figures $\mathrm{D}$ and $\mathrm{E}$ the absciss axis is different from the others for better visualization of the data. Vertical bars represent standard deviation. Different letters mean statistically significant differences $(P=0.05) n=3$.

enquanto no hipocótilo, a atividade aumentou rapidamente das 12 às 18 h00.

A concentração de carboidratos apresentou grandes variações na maioria dos órgãos (tabela 1). A sacarose foi o principal açúcar livre encontrado, o que é evidenciado pela razão sacarose:monossacarídeos maior que $1 \mathrm{~cm}$ na maioria dos órgãos. O epicótilo e o eófilo apresentaram as maiores concentrações de carboidratos, principalmente de madrugada, quando são encontradas as maiores concentrações. Apesar destas variações na concentração, a razão sacarose:monossacarídeos permanece maior que $1 \mathrm{~cm}$ durante todo o dia. No caso da raiz e do hipocótilo, as maiores concentrações de sacarose são observadas no início da noite, mantendo-se altas durante a madrugada. A raiz apresenta um brusco aumento na concentração de sacarose entre $12 \mathrm{~h} 00$ e $18 \mathrm{~h} 00$, enquanto a menor 
Tabela 1. Concentração de carboidratos solúveis ( $\mu \mathrm{g} \mathrm{mg}^{-1}$ de massa seca) e razão sacarose:monossacarídeo nos diferentes órgãos de plântulas de $H$. courbaril ao longo do dia. Letras diferentes correspondem a diferenças significativas entre os horários ao longo do dia para cada órgão $(P=0,05) n=3$. (sac $=$ sacarose; glc $=$ glucose; fru $=$ frutose $)$.

Table 1. Soluble carbohydrates concentration $\left(\mu \mathrm{g} \mathrm{m}^{-1}\right.$ dry mass) and sucrose:monossacharides ratio in the different organs of $H$. courbaril plantlets along the day. Different letters mean statistically significant differences within the same organ $(P=0.05) n=3$. (sac $=$ sucrose; glc $=$ glucose; fru $=$ fructose $).$

\begin{tabular}{|c|c|c|c|c|c|}
\hline Horas & 0 & 2 & 6 & 12 & 18 \\
\hline \multicolumn{6}{|c|}{ Raiz } \\
\hline $\mathrm{sac}$ & $12,96 \pm 10,36^{\mathrm{ab}}$ & $14,38 \pm 12,42^{\mathrm{ab}}$ & $15,30 \pm 4,52^{\mathrm{ab}}$ & $6,00 \pm 7,09^{b}$ & $27,54 \pm 13,28$ \\
\hline glc & $0,53 \pm 0,42^{\mathrm{a}}$ & $0,50 \pm 0,31^{\mathrm{a}}$ & $1,20 \pm 1,33^{\mathrm{a}}$ & $0,56 \pm 0,73^{\mathrm{a}}$ & $1,43 \pm 1,08^{a}$ \\
\hline fru & $0,42 \pm 0,36^{\mathrm{a}}$ & $0,39 \pm 0,28^{a}$ & $0,91 \pm 0,94^{\mathrm{a}}$ & $0,40 \pm 0,35^{\mathrm{a}}$ & $0,52 \pm 0,59$ \\
\hline razão & 13,68 & 16,30 & 7,27 & 6,26 & 14,11 \\
\hline \multicolumn{6}{|c|}{ Hipocótilo } \\
\hline $\mathrm{sac}$ & $17,74 \pm 3,68^{\mathrm{ab}}$ & $17,11 \pm 6,00^{\mathrm{ab}}$ & $11,18 \pm 9,47^{b}$ & $13,65 \pm 3,25^{\mathrm{ab}}$ & $28,86 \pm 16,04$ \\
\hline glc & $1,00 \pm 0,25^{\mathrm{a}}$ & $1,10 \pm 0,70^{\mathrm{a}}$ & $2,38 \pm 2,77^{a}$ & $0,55 \pm 0,64^{\mathrm{a}}$ & $0,45 \pm 0,27^{a}$ \\
\hline fru & $0,88 \pm 0,37^{a}$ & $1,08 \pm 0,82^{\mathrm{a}}$ & $1,12 \pm 0,94^{\mathrm{a}}$ & $1,01 \pm 0,93^{\mathrm{a}}$ & $0,50 \pm 0,26$ \\
\hline razão & 9,45 & 7,84 & 3,20 & 8,71 & 30,24 \\
\hline \multicolumn{6}{|c|}{ Cotilédone } \\
\hline $\mathrm{sac}$ & $6,27 \pm 5,85^{\mathrm{ab}}$ & $2,91 \pm 1,83^{\mathrm{b}}$ & $7,23 \pm 3,41^{\mathrm{ab}}$ & $3,19 \pm 2,28^{\mathrm{ab}}$ & $15,81 \pm 13,75^{a}$ \\
\hline glc & $2,13 \pm 2,80^{\mathrm{a}}$ & $5,55 \pm 4,23^{\mathrm{a}}$ & $6,32 \pm 2,18^{a}$ & $4,18 \pm 2,13^{\mathrm{a}}$ & $0,58 \pm 0,48^{a}$ \\
\hline fru & $2,15 \pm 3,51^{b}$ & $6,53 \pm 5,15^{\mathrm{ab}}$ & $11,71 \pm 8,38^{\mathrm{a}}$ & $6,27 \pm 3,25^{\mathrm{ab}}$ & $0,36 \pm 0,04^{b}$ \\
\hline razão & 1,47 & 0,24 & 0,40 & 0,31 & 16,82 \\
\hline \multicolumn{6}{|c|}{ Eófilo } \\
\hline $\mathrm{sac}$ & $23,80 \pm 1,30^{\mathrm{ab}}$ & $29,84 \pm 9,14^{a}$ & $9,79 \pm 0,75^{\mathrm{c}}$ & $16,77 \pm 7,91^{\mathrm{bc}}$ & $10,77 \pm 9,70^{\circ}$ \\
\hline glc & $2,53 \pm 0,87^{\mathrm{ab}}$ & $4,34 \pm 1,97^{\mathrm{a}}$ & $1,58 \pm 1,01^{\mathrm{b}}$ & $2,58 \pm 1,69^{\mathrm{ab}}$ & $0,70 \pm 1,00^{\mathrm{b}}$ \\
\hline fru & $2,16 \pm 1,09^{\mathrm{ab}}$ & $4,19 \pm 0,99^{\mathrm{a}}$ & $1,79 \pm 1,37^{\mathrm{b}}$ & $1,19 \pm 0,60^{\mathrm{ab}}$ & $0,97 \pm 1,50^{b}$ \\
\hline razão & 5,08 & 3,50 & 2,91 & 4,44 & 6,46 \\
\hline \multicolumn{6}{|c|}{ Epicótilo } \\
\hline $\mathrm{sac}$ & $29,58 \pm 8,81^{\mathrm{a}}$ & $33,92 \pm 8,20^{\mathrm{a}}$ & $15,14 \pm 9,34^{b}$ & $11,69 \pm 1,24^{b}$ & $14,75 \pm 6,29^{b}$ \\
\hline glc & $2,44 \pm 0,89^{\mathrm{b}}$ & $17,75 \pm 6,87^{a}$ & $2,31 \pm 2,23^{b}$ & $5,04 \pm 3,18^{\mathrm{b}}$ & $2,88 \pm 2,89^{b}$ \\
\hline fru & $2,34 \pm 1,25^{\mathrm{ab}}$ & $5,31 \pm 3,12^{\mathrm{a}}$ & $1,36 \pm 1,05^{\mathrm{b}}$ & $1,37 \pm 0,21^{\mathrm{b}}$ & $1,65 \pm 1,28^{b}$ \\
\hline razão & 6,19 & 1,47 & 4,12 & 1,82 & 3,25 \\
\hline \multicolumn{6}{|c|}{ Metáfilo } \\
\hline $\mathrm{sac}$ & $22,28 \pm 2,75^{\mathrm{a}}$ & $4,65 \pm 2,94^{\mathrm{c}}$ & $0,86 \pm 0,18^{\mathrm{c}}$ & $6,32 \pm 1,86^{c}$ & $13,76 \pm 3,02^{b}$ \\
\hline glc & $15,92 \pm 5,56^{\mathrm{a}}$ & $0,49 \pm 0,27^{b}$ & $0,38 \pm 0,43^{b}$ & $16,74 \pm 7,29^{a}$ & $21,33 \pm 7,65^{a}$ \\
\hline fru & $6,57 \pm 0,40^{\mathrm{b}}$ & $0,60 \pm 0,04^{b}$ & $0,05 \pm 0,07^{\mathrm{b}}$ & $12,76 \pm 9,07^{b}$ & $22,81 \pm 3,33$ \\
\hline razão & 0,99 & 4,27 & 2,00 & 0,21 & 0,31 \\
\hline
\end{tabular}

concentração de sacarose no hipocótilo ocorre às 6 horas, embora a grande alteração na razão entre sacarose e monossacarídeos também ocorra entre as 12 e as 18 horas. Os únicos órgãos que apresentaram concentrações de monossacarídeos superiores às de sacarose foram os cotilédones e o metáfilo. Os cotilédones apresentam uma alta concentração de carboidratos às 18 horas e a concentração cai até as 2 horas, sendo que apenas a 0 hora há mais sacarose livre do que monossacarídeos. No caso do metáfilo, há um grande aumento de açúcares no início da noite, seguido de uma queda brusca ao longo da madrugada. 


\section{Discussão}

Santos e Buckeridge (2004) mostraram que os principais drenos de carbono oriundo da mobilização do xiloglucano de reserva na plântula de Hymenaea em desenvolvimento são o epicótilo e o metáfilo, seguidos do hipocótilo e da raiz. A importação de sacarose dos cotilédones é praticamente nula. Como mostrado na figura 1, a atividade de SuSy no epicótilo é a mais baixa de todos os órgãos, sugerindo que esta enzima, embora importante no metabolismo de carboidratos, não deve ser a responsável direta pela degradação da sacarose nas relações de fonte e dreno como visto em tomate (Sung et al. 1989; Wang et al. 1993). A atividade pode ser baixa ainda porque, embora o meristema apical esteja incluído nesse órgão, tal região representa uma pequena massa em relação à massa total do órgão e o efeito de seu metabolismo acaba sendo diluído na preparação do extrato bruto.

Diversos outros processos podem estar associados à atividade de SuSy como a síntese de polissacarídeos de parede e de glicoproteínas que consomem grande parte da UDP-glicose produzida na célula (Duncan et al. 2006). O fato de terem sido observadas variações na atividade ao longo do dia (como observado em Chen \& Chourey 1989), mostra a existência de um complexo mecanismo de controle da atividade, vinculado a diferentes processos metabólicos ou à coordenação das mudanças no fluxo de carbono dentro da planta frente às oscilações circadianas das duas fontes de carbono. Considerando que as variações na atividade foram independentes nos vários órgãos da planta com picos de atividade em diferentes horários, a enzima provavelmente está associada a diferentes processos fisiológicos nos diferentes órgãos.

Um fator importante na interpretação dos dados é a provável sincronia das duas fontes de carbono da planta no período da coleta (Santos \& Buckeridge 2004, Amaral 2005). No caso do eófilo, por exemplo, há uma mudança de fonte para dreno ao longo do dia, em função do estabelecimento da fotossíntese às $6 \mathrm{~h} 00$. Além disso, os dados apresentados por Santos e Buckeridge (2004) referem-se apenas ao dreno das reservas cotiledonares, pois o carbono adquirido por fotossíntese não foi marcado.

Nas primeiras horas na presença de luz (início da fotossíntese), ocorrem alterações no metabolismo de carbono da plântula que se refletem no padrão de atividade da invertase insolúvel (figura 2). A única exceção é a raiz (figura 2A) cuja atividade não apresenta variações estatisticamente significativas, embora haja uma ligeira queda às 6h00. Apesar de este ser o único órgão da planta que não fica exposto às variações de disponibilidade de luz, espera-se que as raízes percebam as variações metabólicas que ocorrem nas outras partes da planta, seja através de sinalização específica com fitoreguladores, seja através de variações na disponibilidade de carboidratos, uma vez que tais moléculas podem atuar como sinalizadores (Rolland et al. 2002, Gibson 2005).

Entre os órgãos cuja atividade de invertase insolúvel varia ao longo do dia, podemos separar dois grupos: os que apresentam um aumento ao amanhecer, hipocótilo, epicótilo e metáfilo (figura $2 \mathrm{~B}, \mathrm{E}$ e F), e os que apresentam uma redução ao amanhecer, cotilédone e eófilo (figura $2 \mathrm{C}$ e D). É interessante notar que o segundo grupo é formado pelos dois órgãos que atuam como fontes de carbono na planta. Como essas duas fontes funcionam em momentos distintos, no entanto, esperaria-se que o padrão de atividade de invertase insolúvel dos eófilos e dos cotilédones fosse inverso, uma vez que estes órgãos exportam sacarose em momentos distintos do dia. Porém outros processos fisiológicos tais como expansão celular (Winter \& Huber 2000), partição de sacarose e transdução de sinais de estresse (Sturm 1999) poderiam, portanto, estar associados a tais variações de atividade. As dosagens de invertase solúvel ácida mostram uma clara diferença entre o metabolismo noturno e o diurno (figura 3). Aparentemente, há uma grande alteração no metabolismo de carboidratos em todos os órgãos às $2 \mathrm{~h} 00$, coincidindo com o período observado para o pico de atividade das enzimas de degradação do xiloglucano (Amaral 2005).

Embora o vacúolo não esteja diretamente ligado à degradação do xiloglucano e à conversão de seus monossacarídeos constituintes em sacarose, esta organela participa diretamente do metabolismo de carbono. $\mathrm{O}$ vacúolo é um importante elemento tanto no armazenamento quanto na compartimentalização dos produtos de degradação, sendo essencial nos ciclos de síntese e degradação da sacarose que ocorrem nas células ("ciclos fúteis", Nguyen-Quoc \& Foyer 2001). A existência de diferentes tipos de vacúolos é evidenciada por diferentes isoformas de proteínas do tonoplasto, que podem ser utilizadas como marcadores de função desses vacúolos (Jauh et al. 1999).

A invertase neutra apresentou a menor atividade entre as isoformas, assim como a maior diversidade de comportamento ao longo do dia (figura 4). A amplitude das diferenças entre as atividades foi tão grande que forçaram o uso de dois eixos distintos na figura. Enquanto hipocótilo e cotilédone apresentam grandes aumentos ao final do dia (18h00), os órgão "aéreos" (eófilo, epicótilo e metáfilo) apresentam um pico ao meio dia, com queda da atividade ao fim do período luminoso (18 horas). A raiz, por outro lado, não apresentou 
variações na atividade ao longo do dia. $\mathrm{O}$ aumento da atividade de invertase neutra, portanto, parece estar mais associado à fotossíntese do que à mobilização da reserva de xiloglucano, uma vez que aumenta nas partes aéreas da planta durante o período de fotossíntese. A grande diferença na atividade entre $18 \mathrm{~h} 00$ e $0 \mathrm{~h} 00$ nos cotilédones e no hipocótilo (figuras 4B e C) sugere uma profunda alteração no metabolismo de sacarose no período da noite nestes órgãos. Estes dois órgãos apresentaram as atividades mais altas da isoforma às 18 h00, comparável às atividades das demais isoformas (um aumento da ordem de 6 vezes em relação aos demais órgãos).

No caso do metáfilo, ao compararmos as figuras $1 \mathrm{~F}, 2 \mathrm{~F}, 3 \mathrm{~F}$ e $4 \mathrm{~F}$, nota-se que os picos de atividade das enzimas se alternam, havendo sempre uma enzima com atividade crescente. Às $2 \mathrm{~h} 00$, há um pico de invertase ácida, às 6 h00 há um pico de invertase insolúvel, ao meio dia e à meia noite há picos de SuSy. Tal alternância de atividades mostra uma intrincada coordenação no metabolismo da sacarose e pode estar ligada às alternâncias entre as duas fontes de carbono da folha em desenvolvimento (o principal dreno de sacarose da planta). No caso dos cotilédones, por outro lado, há um aumento de todas as enzimas de hidrólise de sacarose às 18h00. Tal diferença pode ser devida ao fato de este órgão funcionar apenas como fonte, ainda assim exerce tal função de forma variável ao longo do dia. O aumento da capacidade hidrolítica, portanto, deve estar ligado à preparação para exportação de carboidratos no período da madrugada, quando são obtidas as maiores atividades das enzimas de degradação do xiloglucano.

A análise de carboidratos também mostrou grandes oscilações nos teores de açúcares solúveis nos órgãos ao longo do dia (tabela 1). No caso do metáfilo há uma queda brusca no teor de carboidratos entre $0 \mathrm{~h} 00$ e $2 \mathrm{~h} 00$, concomitante com um grande aumento de atividade da invertase ácida, sugerindo que os carboidratos poderiam estar acumulados no vacúolo e durante o período a sacarose teria sido hidrolisada. A concentração de carboidratos se mantém baixa ao longo do dia voltando a crescer apenas no fim do dia (18h00), horário no qual não é encontrado pico de atividade de nenhuma das enzimas de hidrólise, o que possibilitaria o aumento na concentração de sacarose observado entre as $18 \mathrm{~h} 00 \mathrm{e}$ 0h00. Nota-se também que a maior concentração de monossacarídeos livres é encontrada neste órgão.

Considerando que o metáfilo é o principal dreno de carboidrato da plântula, pode-se propor um modelo de acúmulo e consumo dos carboidratos solúveis. Primeiramente, haveria o acúmulo de monossacarídeos livres na célula devido à hidrólise associada ao estabelecimento de dreno de sacarose nos vasos condutores, promovida pela invertase insolúvel. Esse acúmulo dos monossacarídeos livres favorece a síntese de sacarose no citoplasma da célula. Esta sacarose é então armazenada temporariamente no vacúolo sendo hidrolisada pela invertase solúvel ácida durante a madrugada, possivelmente devido a uma queda nas taxas de importação. No intervalo entre $0 \mathrm{~h} 00$ e 2h00, 75 \% da sacarose deste órgão é utilizada. A razão para tudo isso é a manutenção de um gradiente osmótico que cria um fluxo de sacarose que tem como destino o principal dreno de carbono da plântula.

As altas concentrações de sacarose, que se refletem em elevadas razões sacarose:monossacarídeo de raiz, hipocótilo e epicótilo, podem ser explicadas pelo fato de serem órgãos com baixas taxas de expansão e com grande quantidade de tecidos condutores. Ou seja, a sacarose nestes órgãos estaria sendo transportada para os drenos ativos. Embora estes órgãos compreendam os meristemas apicais, a biomassa destes tecidos em relação ao órgão inteiro é muito reduzida, justificando não considerá-los como um dreno ativo e corroborando as observações de Santos \& Buckeridge (2004).

Ao contrário do esperado, as concentrações dos carboidratos solúveis no cotilédone foram baixas durante a madrugada. Isto sugere que os monossacarídeos originados da mobilização do xiloglucano de reserva seriam prontamente transformados em sacarose, para imediata exportação, ou em amido transitório (Tiné et al. 2000). Como os carboidratos são transportados pela plântula via floema e o carregamento deste pelas células companheiras é um processo ativo, seria possível criar nos feixes vasculares do cotilédone (fonte) uma alta concentração local de sacarose mesmo que a concentração média de sacarose no parênquima de reserva seja baixa. Isso permitiria a exportação da sacarose sem que altas concentrações fossem atingidas no tecido de reserva, o que poderia inibir o processo de degradação do xiloglucano por feedback negativo. A queda na concentração de sacarose durante o dia observada no eófilo, poderia ser explicada pelo mesmo mecanismo, uma vez que durante o dia a folha está fotossinteticamente ativa exportando carboidratos e sintetizando amido transitório. Neste caso, o processo a ser preservado do feedback negativo seria a fotossíntese.

A multiplicidade de funções da sacarose dentro da fisiologia da planta reflete a diversidade de funções das invertases. A compreensão deste metabolismo é um passo no sentido de entender a necessidade de tantos genes para codificar isoenzimas que hidrolisam sacarose. $\mathrm{O}$ fato de o padrão de atividade das diferentes isoformas 
de invertase ser distinto reforça a idéia que tais enzimas estejam associadas a diferentes processos metabólicos (Sturm 1999). Isso evidencia a importância dessas enzimas em diferentes aspectos do metabolismo de sacarose além das relações de fonte e dreno como regulação osmótica e crescimento celular (Sturm \& Tang 1999). Além disso, ao considerarmos que os carboidratos atuam não apenas como substrato para o metabolismo, mas também como moléculas sinalizadoras afetando a expressão de diversos genes (Rolland et al. 2002, Blässing et al. 2005), a importância da atividade de enzimas do catabolismo de sacarose pode ser estendida a diversos outros processos por possibilitar a alteração das concentrações locais de carboidratos e da razão sacarose:monossacarídeos.

Agradecimentos - à Fapesp, Fundação de Amparo a Pesquisa do Estado de São Paulo, pelo apoio financeiro. Processo $\mathrm{n}^{\mathrm{o}}$ 04/12194-5 e 04/10159-8.

\section{Referências bibliográficas}

AMARAL, L.M.V. 2005. Metabolismo de carboidratos estruturais e de reserva em cotilédones de Hymenaea courbaril L. (Jatobá). Tese de doutorado, Universidade de São Paulo, São Paulo.

BARRIGA, M.L.2003. Fitomonitoração e modelagem de fotossíntese em jatobá (Hymenaea courbaril L.) com redes neurais artificiais. Tese de doutorado, Universidade de São Paulo, São Paulo.

BLÄSSING, O.E., GIBON, Y., GÜNTHER, M., HÖHNE, M., MORCUENDE, R., OSUNA, D., THIMM, O., USADEL, B., SCHEIBLE, W. \& STITT, M. 2005. Sugars and circadian regulation make major contributions to the global regulation of diurnal gene expression in Arabidopsis. The Plant Cell 17: 3257-3281.

BUCKERIDGE, M.S. \& DIETRICH, S.M.C. 1990. Galactomannan from Brazilian legume seeds. Revista Brasileira de Botânica 13:109-112.

CHEN, Y.C. \& CHOUREY, P.S. 1989. Spatial and temporal expression of the two sucrose synthase genes in maize: immunohistological evidence. Theoretical and Applied Genetics 78:5553-559.

DUBOIS, M., GILLES, A., HAMILTON, J.K., RERBERS, P.A. \& SMITH, F. 1956. Colorimetric method for determination of sugars and related substances. Analitical Chemistry 28:350-355.
DUNCAN, K.A., HARDIN, S.C. \& HUBER S.C. 2006. The three maize sucrose synthase isoforms differ in distribution, localization, and phosphorylation. Plant Cell Physiology 47:959-971.

FARRAR, J., POLLOCK, C. \& GALLAGHER, J. 2000. Sucrose and the integration of metabolism in vascular plants. Plant Science 154:1-11.

GIBSON, S.I. 2005. Control of plant development and gene expression by sugar signaling. Current Opinion in Plant Biology 8:93-102.

JAUH, G.Y., PHILLIPS, T.E. \& ROGERS, J.C. 1999. Tonoplast intrinsic protein isoforms as markers for vacuolar functions. The Plant Cell 11:1867-1882.

LEE, Y. \& LANGENHEIM, J.H. 1975. Systematics of the genus Hymenaea L. (Leguminosae, Caesalpinioideae, Detarieae). University of California Publications in Botany, 69, Berkeley.

NGUYEN-QUOC, B. \& FOYER, C.H. 2001. A role for futile cycles involving invertase and sucrose synthase in sucrose metabolism of tomato fruit. Journal of Experimental Botany 52:881-889.

ROLLAND, F., MOORE, B. \& SHEEN, J. 2002. Sugar sensing and signalling in plants. The Plant Cell (suplement): 185-205.

SANTOS, H.P. \& BUCKERIDGE, M.S. 2004. The role of the storage carbon of cotiledons in the establishment of seedlings of Hymenaea courbaril under different light conditions. Annals of Botany 94:819-830.

STURM, A. 1999. Invertases. Primary structures, functions, and roles in plant development and sucrose partitioning. Plant Physiology 121:1-7.

STURM, A. \& TANG, G.Q. 1999. The sucrose-cleaving enzymes of plants are crucial for development, growth and carbon partitioning. Trends in Plant Science 4:401-407.

SUNG, S.S., XU, D.P. \& BLACK, C.C. 1989. Identification of actively filling sucrose sinks. Plant Physiology 89:1117-1121.

TAIZ, L. \& ZEIGER, E. 2003. Photosynthesis: Carbon reactions. In Plant physiology. (L. Taiz \& E. Zeiger, eds.). Sinauer Associates, Sunderland, p.145-168.

TINÉ, M.A.S., CORTELAZZO, A.L. \& BUCKERIDGE, M.S. 2000. Xyloglucan mobilisation in cotyledons of developing plantlets of Hymenaea courbaril L. (LeguminosaeCaesalpinoideae). Plant Science 154:117-126.

WANG, F., SANZ, A., BRENNER, M.L. \& SMITH, A. 1993. Sucrose synthase, starch accumulation, and tomato fruit sink strength. Plant Phisiology 101:321-327.

WINTER, H. \& HUBER, S.C. 2000. Regulation of sucrose metabolism in higher plants: localization and regulation of activity of key enzymes. Critical Reviews in Plant Sciences 19:31-67. 